\title{
Implication of Social Media on the Students' Academic Performance in campus China
}

\author{
Fan Kang \\ Wuhan polytechnic university, Wuhan, China \\ E-mail:Kangfan2004@163.com
}

Keywords: Social Media, Accessibility, Attitude, Academic Performance

\begin{abstract}
The study examines social media: its implication on academic performance of students in campus, China. The researchers considered the influence of social media on students' attitudinal disposition, academic performance, accessibility and their social lives. The study utilized a survey method using the SPSS package to analyze the data. A simple percentage was used to interpret the results. The result shows that $51.7 \%$ of students agreed that social media influenced their academic performance positively in campus China. About $61.1 \%$ of Students agreed that social media has impacted positively on the social lives, hence, improving linkages with new friends, acquiring new skills, and learning good habits. While $73.8 \%$ of the campus students have access to internet which has enabled them have accounts with 2go, BBM, Facebook and Whatsapp. About $61.9 \%$ of campus Students agreed that social media affect their attitude positively. The researcher recommends among others that the government should include e-learning scheme of work compulsory and provide internet service to all the schools in China in order to tackle the hurdle at Computer Based Examination (CBE).
\end{abstract}

\section{INTRODUCTION}

Human beings are said to be gregarious in nature that is to say they are sociable as such will like to interact with one another in their social milieu. The word "Social" connotes the way people communicate/interact with one another in our society. Media is the platform used to allow movement or communication with other parts. . Social Media can be defined as the utilization of all the Information and Communication Technology resources both software and hardware components to reach out to others or it refers to the wide range of Internet-based and mobile services that allow users to participate in online exchanges. The advent of social media has enabled humans exploit the advantages associated with it thereby reducing the cost and danger that can be incurred by humans either by Land, Air or Water with the intent to achieve business transaction or mileage in general. The pecuniary advantage can be educational/Research, Business, Information gathering or other reasons outside the ones mentioned.

Ostensibly, social media serve as a vehicle or tool that afford people the opportunity to exchange photos, videos, share news, stories, post their thoughts on blogs, and participate in online discussions. The platform allows individuals, companies, organizations, governments, and parliamentarians to interact with large numbers of people.

\subsection{The Emergence of Social Media}

The first Social Media Site is called SixDegrees.com it emerged in 1997. It was named after the six degrees of separation theory and lasted from 1997 to 2001. Its debut enable users create profiles and list their Friends. From SixDegrees the internet moved into the era of blogging and instant messaging. Here people were able to communicate with a blog as well as other readers. "Weblog" was coined by Jorn Barge, an early blogger that was the editor of the site 'Robot Wisdom' . From there ICQ was born and most members of Generation X remember ICQ and the service that was created.Shortly thereafter, America Online with AOL's instant massager became prominent in the social media line-up Back in 2000, the website that was popular was Myspace which was set up as a profile and to make friends leading to facebook. But before then Linkedln which was produced to achieve professionals’ people to connect with each other to network find jobs and socialize. 
By year 2000 around 100 million people had access to the internet and it became quite common for people to be engaged socially online of cause. In February 4, 2004 Facebook was launched by Mark Zucherberg with his college roommates and fellow Harvard University Students Eduardo Saverin (Carson,N. 2010). The Website was initially limited by the founders to Harvard Students but was later expanded to other Colleges in the Boston area the Ivy League(Company, Timeline, 2007) and gradually most University in Canada and United States(Rosemarin, R. 2006).Facebook and Twitter were known for text messaging or SMS this achievement was credited to Jack Dorsey, Business Stone, Noah Glass and Evan Williams to create Twitter, service that had the unique distinction of allowing users to send tweet of 140 characters or less. In July 2012, Twitter had an estimated 517 million users; of whom 10 million were in Canada.

By 2010, the rest of the websites like Flicklr was introduced it was most popular for photo sharing sites, others includes photo bucket and Instagram. Today Instagram is gaining popularity as one of the top Social Media Sites to include business cards and other media. David Karp designed Tumlr for microblogging websites and he owns Yahoo, the site that could be seen sprouting up in late 2000s. Other website invented are Foursquare, Pinteret, Google Buzz, Loopt, Blippy and Groupon.

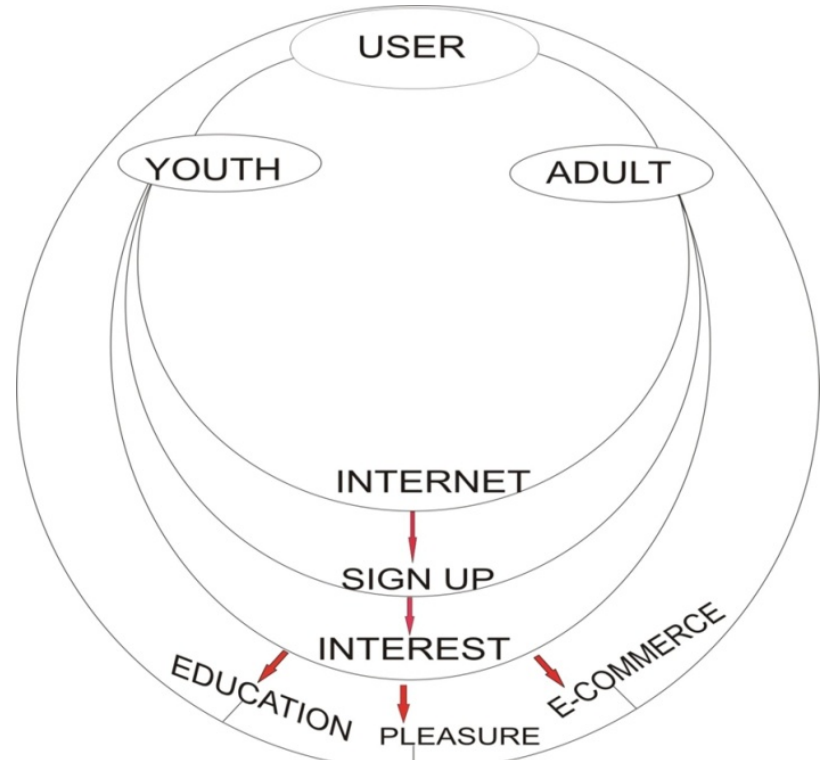

Fig: 1 authors’ Computation

The process of social media starts with the user. As shown in fig1 above. Both the Youth and the Adult make up the User. The entry point into the social media is via the Internet. Once the user launches the browser he/she is expected to be authenticated through a sign-up process. The sign up process entails that the user on the first visit to the internet have to provide all information such as name, sex, Date of Birth, Address, Country, Location, Phone Number email address and password so as to be authenticated. The confirmation of the email address and the password terminate the authentication process of sign-up.

In the social media environment whether Facebook, Tweeter or BBM etc. the user decides the varieties of sites to visit whether for Education purpose, Pleasure seeking purpose or e-commerce purpose.

The user whose motive is for educational purpose explores materials for research purposes, while some seek information about other Countries, sports, entrance admission and so on. The curious ones engage in diligent search to enable them do assignment and improve their academic performances.

In another vein, many users resort to pleasure seeking. This is an attitude developed in users based on their ego. Most of them have negative ego seeking while others may be positive. Some snap photos and publish on walls of their friends; others may be watching/ downloading video that is sent to them by their social media friends and chatting with friends (group meeting/cooperation) 
synchronously or asynchronously on the network. The attitude developed by users in chatting with friends sometimes takes hours which could have been channel to other profitable activities especially where users choose to watch pornographic movies online.

The last group of activities that are carried out by a user is the e-commerce. Series of e-booking especially those that wish to travel can book ahead of time to enable them make it fast. Some advertisements are done online such that interested users access such information. The social media has equally portended a veritable tool for e-banking such that users can easily transfer money(school fees, Tuition fee etc) at home without going to the Bank. This feat of using social media has helped users reduce the volume of cash carrying by hand on daily basis thereby reducing the risk of robbery attack.

1.2 The pros of social media

(a) Educational Purpose

Assignment: When students have questions about a class assignment they can easily post a message asking if anyone can help. They can also write a specific question to the teacher on a wall that other students can see. This allows the whole class to have access to the feedback from the teacher.

Information: Students can explore social media sites and joining groups online to obtain vital information relating to academics and social lifestyles. In School, the teacher can direct students to a particular online resource they can easily share among other students. If the teacher wants the class to visit a particular site all they have to do is tweet the website and the entire class can view it with one click.

Research: It is very useful for teachers to be able to post on social media sites about class activities, homework, assignments, Research topics and even school events. This helps the teachers and students to stay on the same page about what is going on at school and even ask question on research need. Sites like Facebook also allow teachers to easily communicate through private messages to students without having to leave phone messages and wait for a call back. The Students undergoing Distance learning can be in one country and access materials or send their projects via social media with ease.

(b) Attitudinal Purpose

Chatting: Through social media, individuals can chat in a flash, regardless of geographical location. There is no limit to the amount of people it could potentially reach all at no extra cost. People can send messages synchronously or asynchronously.

Unlike the traditional methods where people have to travel distances, Social Media like Tweeter can be used 24/7 without much cost for chatting.

Sharing Resources: With social media various resources like video and photos and news can be shared. This enables people to be kept abreast events, happening in the world without having extra cost. Loved ones send video of recorded events from one country to another via social media without transport cost. It has become easy for Students to have pictures of animals, countries and people etc.to facilitates knowledge economy.

Video conferencing: Many people today use video conferencing to reach to many at a time. Video conferencing is a one to many conversations where one person could establish a link with many people to pass information as quickly as possible without much cost.

(c) Accessibility Purpose

E-banking: social media enables people transact e-banking business without necessarily going to bank. For example Google+ can be used to send money to anywhere in the world. This has ameliorated the high risk of carry cash to the bank as well as save time.

Advertisement: Social media's adaptability makes advertisement generally more flexible. Information can be updated, altered, supplemented, discussed and advertised in a way completely unknown to a printed advertisement, a newspaper article or magazine feature. What is more, information can be published in seconds, making it possible for businesses to ensure that their content is always up to date.

E-booking: People use social media platform for booking their flight ticket ahead of time without 
necessarily going to the Airport. Unlike the traditional method where individual must travel to the Airport, queue up for hours and sometimes missed their flight because they were not able to meet up on time.

The cons of social media

Distraction: using social media in the classroom portends major distraction to the students during lessons. Students could easily be sidetracked during lessons and it could be difficult for teachers to tell who is paying attention or not. Students might take advantage of being able to access social media in the classroom and use it for personal interactions instead of for school related activities. If students are not closely monitored it will be hard to know how if they are using social media properly.

Cyber Attacks: Some people have experienced cyber-attacks through social media websites. People write some injurious and hurtful messages targeting other students.

Pornographic sites: social media expose many students to access naked pictures and have sexual desire. This is one of the challenges threatening the existence of social media in the World.

The rest of the paper is divided into literature review, methodology findings conclusions and recommendations.

\section{LITERATURE REVIEW}

\section{Introduction}

The Chapter discusses Social Media: its implication on academic performance of students in campus Municipality. For the purpose of this research, the authors undertook a comprehensive review of the Literature Review to decipher concepts on the attitude of students on social media, their accessibility on the social media sites and academic performance dynamics.

2.1 Attitude of Students on Social Media

In the modern world, the term Social media is linked with communication. This is because many people both young and old exploit disposable gadgets to reach out to others. Julia Wood 2004, opined that "communication is a systematic process in which individuals interact with and through symbols to create and interpret meanings. In today's highly technologically oriented world, people have begun to communicate in a new way which include inter alia, telephones, cell telephone, smartphones, handheld devices, tablets, emails, video conferencing, instants messaging or text messaging. Communication is the essence of science and that without it the society will be blind.

In campus Municipality Abuja, many people especially students spend lots of time on site creating profile, updating or doing research concerning their career or academic work, while some just use it to chat with friends, post latest pictures of event they attended. According to the questionnaire used for this project, 73.8\% who answered the questionnaire has access to the internet, and they are connected to one social network or the other.

The increasing demand for social media communicators has become a global vagary. It started as an eclipse and has suddenly engulf the world as a social norm, a way of life among the people in the globe (Boyd, 2007).The attitude of teenagers and youths especially students in Nigeria and other parts of the World have embraced these sites as a way to connect with their friends, make new once, share information, photos of their activities such as birthday, photo with friend in class etc, and showcase their social lives.

It is therefore a common practice among users today given the technological advancement, that social media has become a hubby or activity that is done primarily on the internet, with sites like MySpace, Face book, Skype, etc (Coyle et al., 2008).

Lewis. 2008. Observed that with the advent of social Media Sites it has become easy to get information on nearly every issue around the globe once someone accepts you as friend every information sent to him will automatically be available in his mail. Before now it was not easy accessing information, you need to buy newspaper, stay glue to your Television set or Radio to get information. Internet has revolutionized everything and social Media has become more flexible.

Young et al., 2009, have examined their profiles to determine why and to what extent they are keen on posting their entire identity, sharing pictures and videos, and indicating their religious 
affiliations, marital status, and political orientations on the internet. These users interact with others, exchange information about their interests, raised discussions about new topics, follows news about specific topics on different Social Networking Sites.

\section{Social Media Accessibility}

In the contemporary time students prefer pressing buttons to carrying out academic research through the orthodox means of flipping pages of paper. However many factors may be responsible for the skewed behaviors and divergent interest of users. These factors include; psychological effects; individual self-discipline, self-regulation concern and human adaptability concerns.

Zwart, Lindsay, Henderson, \& Phillips, 2011 unanimously agreed that users have divergent interest and yet stand to benefit from using Social Media Sites. The benefits includes: increasing the technological competency levels of frequent users of social media, reduces barriers to group interaction and communications such as distance and social/economic status; give individuals a sense of belonging among users of the same Social Media Site, provides greater access to information and information sources, encouraging greater social interaction via electronic mediums and create room for creativity among individuals.

Chen, \& Bryer, 2012 gave a scintillating insight on the accessibility and frequency of usage on the Social Media today. According to them, the use of Facebook alone has over 750 million members, Twitter having over 177 million tweet per day, and about 3 billion people view Youtube each passing day. The use of social Media sites has been repeatedly found to be the highest among those between the ages of 18-29 (Rainie, 2011); while the fastest growing segment utilizing Social Media Site since 2008 has been among those age 35 and older (Hampton, Goulet, Rainie, \& Purcell, 2011, p. 8). Approximately 61\% of teens age 12-17 utilize Social Media Site to send messages to their friends on a regular basis (Lenhart, 2009). Overall, it has been found that women use Social Media Site more than men to communicate and exchange information (Hampton, Sessions-Goulet, Rainie, \& Purcell, 2011). The research carried out for this project female responded more than male.

There are population explosions in Internet access and usage over the last few years. Users are able to build a network of connections that they can display as a list of friends. These friends may be people they have never met before in their life or people they only know or have met in real life. Most people have more friends on social network than they do in real life.

It is important to note that the term 'friend', as used on a social networking site, is different from the way we approach it in the real life. In this project we will use the term as it is used on a social media site.

A research conducted by American Educational Association declared on its annual conference in San Diego, California (2009) that Social Media Site users study less and generated lower grades eventually (21st centuryscholar.org). Similarly, Banquil et al. (2009) found a continuing drop of grades among student users of social networking sites. However, many researchers also found a positive association between use of internet and Social Media Site and academic performance of the student users. Students, using internet frequently, scored higher on reading skills test and had higher grades as well (Linda et al., 2006).

A research conducted by Napoleon, Egedegbe on The Effect of Social Networking Sites on Students' Academic Performance in Girne American University, North Cyprus . Students said Social network provides an effective tool for e-learning $85 \%$ of the respondent believes that social networking sites is an effective tool for e-learning, while $14 \%$ thinks otherwise, and $1 \%$ did not respond to the question. Student who support, thinks that with SNS one can easily submit assignment, without necessary going to meet lecturer face to face. Student can interact with other student on a particular subject and share ideals. Most of the student also agrees on the fact that SNS help them academically in getting educational materials for their assignment and project work. With the help of the internet it is almost possible to get any kind of subject material at your disposal.

\section{RESULT INTERPRETATION}

Examine the influence of social media on students' academic performance

About $51.7 \%$ of students agreed that social media influenced their academic performance 
positively. With the help of the internet it is almost possible to get any kind of subject material at your disposal. It becomes easier for campus student, because the schools have provided the enable environment for students to access the internet with ease such that assignments are facilitated and the resultant effect is high grade at school. Only $7.9 \%$ are of the contrary view that social media influence their academic performance negatively. This implies they spend their time on porn sites and music as well as chatting outside the purview of academic jurisdictions. While $32.5 \%$ has not responded.

Determine the level of accessibility of the social Media among students

About $73.8 \%$ of the campus students have access to internet which enable them have accounts with 2go, BBM, Facebook and Whatsapp. while 26.2\% does not have access to the social media, may be the students are staying with parents or Guardian or are in Schools that have no network connectivity.

Determine the attitude of students on social media in campus

About $61.9 \%$ of campus Students agreed that social media affect their attitude positively. This shows that they make more friends online, have access to useful information and thus do their assignment easier and faster. While $7.1 \%$ said it affects them negatively. This represent some groups that watch porn sites, spend between 4-6hours daily online for music and entertainment at the detriment of their academic welfare. Then $27.8 \%$ has no response. Parents should monitor their wards on the kind of friends they keep online to avoid ineptitude behavior.

\section{Acknowledgment}

Introduced talents start-up capital projects in Wuhan polytechnic university: The augmented reality supported publishing media fusion model in the mobile Internet era. No:20152S05

Humanities and social science project in Hubei province:Origami art innovation application research in the packaging design No:14G234

\section{Reference}

[1] Boyd, D and Ellison, NB (October, 2007), 'Social Network Sites, Definition, History and Scholarship', Journal of Computer Mediated Communication, http : // jcmc. indiana. Edu / vo 113 /issue1 / boyd. ellison.html.

[2] Carlson,Nicholas (2010), At last The full story of How facebook was founded. Business Insider ( online, March 5)

[3] Company Timelines (2007), ('Press Release”).Facebook Retrieved March 5, 2008

[4] Chen, B., \& Bryer, T. (2012), Investigating Instructional Strategies for Using Social Media in Formal and Informal Learning. The International Review of Research in Open and Distance Learning, 13(1), 87-104.

[5] Enriquez, J. (2010), Facebook and Other Online Social Networking Sites Can Lower Grades, Study Says. Retrieved from http : // seerpress. Com / facebook -and- other -online- social -networking- sites -can -lower -gradesstudy- says/ 6935/.

[6] Hampton, K. N., Sessions-Goulet, L., Rainie, L., \& Purcell, K. (2011), Social networking sites and our lives. Washington, DC: Pew Research Center.

(d) The impact of social media on the social lives of students

About $61.1 \%$ of the campus Students agreed that social media has impacted positively on their social lives by increasing the level of meeting new friends, $21.4 \%$ of the students said they had acquired new skills via social media, $12.7 \%$ said social media helped them improve on learning good habits. In the contrary, $0.8 \%$ said social media impacted negatively on their social lives. It has exposed them to learning bad habits with friends at different media sites. 